\section{The impact of using multimedia in English high school classes on students' language achievement and goal orientation}

\author{
Ghanizadeh, Afsaneh $\bowtie$ \\ English Department, Imam Reza International University, Mashhad, Iran (ghanizadeafsane@yahoo.com; \\ a.ghanizadeh@imamreza.ac.ir) \\ Razavi, Azam \\ English Department, Imam Reza International University, Mashhad, Iran (ernika.razavi@gmail.com)
}

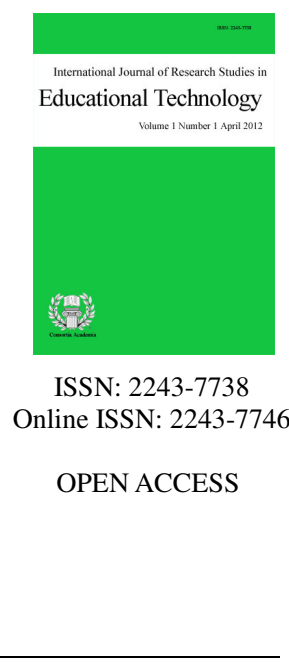

\title{
Abstract
}

The study aimed to examine the effectiveness of using multimedia elements in teaching English for the eighth graders in public schools. For answering the questions of the study, the researchers adopted the experimental approach. The sample of the study consisted of (58) female students from Navid girl high School in an urban setting in Mashhad (a city in Northeast of Iran). The results of a pretest indicated that the participants of the two groups were homogenous with regard to their proficiency level. The researchers divided the sample of the study into two groups, experimental and control group. In addition to official book (prospect 2), the experimental group was exposed to multimedia elements as animations, cartoons, and Power Point Presentation (P.P.P.). But in control group, prospect 2 was taught through traditional chalk and board instruction in the first term of the academic school year (2014-2015). The results of the post-test indicated that using multimedia elements has a positive and significant influence on learners' achievement as well as on their achievement goal orientation (mastery, performance, and avoidance). In particular, students in experimental group tended to adopt a mastery-goal orientation as the result of technology-based instruction. In the light of these results, the study recommended the necessity of implementing multimedia in teaching English.

Keywords: multimedia; CLT method; goal orientation; language achievement 


\section{The impact of using multimedia in English high school classes on students' language achievement and goal orientation}

\section{Introduction}

English has become the most dominate language in the world. As David and Dan (2002) asserted, it is the language of travel, tourism, science, and technology. This universal acceptance and the need for good communication skill in English has created a vast requirement for teaching English around the world. This fact has put a tremendous pressure on educationalists to cope with this demand and to attempt to equip teachers with modern teaching methods and approaches. As society advances, science and technology develop and the Internet emerges, the traditional teaching of English has been greatly challenged by many new ways In Iran. According to educational policy of Iran since 2011, communicative language teaching is used for teaching English in high schools. So English as a language is a communicative tool and the crucial goal of learning English for Iranian students is the future use of English for communication. If the students only emphasize learning the language traditionally instead of using it, then the result will become the failure of English teaching in Iran. The traditional English teaching is teacher-centered and students only passively accept what the teacher has instructed. What's more, the content is boring, so it is quite difficult to stimulate students' interest in English learning. In traditional English teaching mode, students may review the text only through textbooks, reference books and notes after class. It is easy to lose information. Now teachers in Iran are confronted with many issues, such as how to raise students' interest in English learning, how to increase the efficiency of teaching during class. Multimedia for teaching assumes to be a good answer to the above questions. In the multimedia teaching, with eyes looking, ears listening, mouth speaking, hands writing, brains keeping in mind, students develop interest to learning which in turn is expected to enhance academic effectiveness (Li, 2009). Multimedia teaching can create a practical English using environment, in which students can enhance their ability to use English.

Mayer (2001) suggests that learners are able to create a deeper understanding of words when they establish connections between words and pictures than from words or pictures alone. Multimedia has broken through the traditional "blackboard and chalk" teaching style. It has conquer the drawbacks of traditional teaching changing abstract, boring contents into funny, visual, audible, and dynamic ones. Multimedia English teaching combines text, images, audio and video together making English teaching colorful and interesting so as to attract the attention of students and stimulate students' interest in English learning. After the teacher uses multimedia in teaching, students can copy down the materials for after-class learning. In addition, students can look for some information they need through multimedia. The teacher and students also can communicate through the network. In this way English, classroom can be extended to extra-curricular learning and both the teacher and students will make the best use of multimedia. Therefore, it is a movement towards modern English teaching. Consequently, the present study attempts to investigate the effect of using multimedia on the eighth grader English achievement and on their goal orientation in Iran.

\subsection{Foundation of the Study}

In Iran since (2012) and onwards, English has been taught from the first grade in high schools, and a new curriculum, according to CLT approach (communicative language teaching) has been introduced. This curriculum emphasizes the use of the Communicative Approach and a more skills-based approach to foreign language learning. Themes and topics in the textbooks have been chosen to interest and stimulate learners. The Communicative Approach is here understood as an approach that emphasizes meaningful interaction and information exchange. It can be argued that the development of multimedia programs can fit in this approach to language teaching as they emphasize student-centered lessons, and give the learners the opportunity to learn on their own. 
The impact of using multimedia in English classes on students' language achievement and goal orientation

As the main aim of the Iranian syllabus is to develop students' competence in the four skills, and to encourage students to become confident users of English language, multimedia elements can be used to stimulate students' interaction and involvement through the use of more authentic learning environment. The activities are combined with sounds and movements just like in the real world. By using multimedia, skills are easily integrated, since the range of media makes it natural to combine listening, speaking, reading, and writing in a single activity (Warschauer \& Healay, 1998).

\subsection{Research Questions}

This study aims to investigate the impact of using multimedia in English high school classes on students' language achievement and their goal orientation. In so doing, the following research questions are posed.

$>\quad$ Does using multimedia in English high school classes have any significant impact on EFL learner's achievement?

$>\quad$ Does using multimedia in English high school classes have any significant impact on EFL learners' goal orientation?

\subsection{Significance of the Study}

Improving methods of teaching English in Iran is absolutely required as it is the language of modern technology, science, art, politics, medicine, and other subjects. Despite the efforts of Iran Ministry of Education in improving the teachers' abilities through training courses on teaching methods (TTC), teachers always complain about their students' poor proficiency in English. So it is of a great importance to think of new teaching methods and techniques which can be used to promote students' efficiency in learning English. So teachers should endeavor hard to attract the learners' attention and exert efforts to employ a fit planned program for this purpose. At the Ministry of Education in Iran, there is a recent tendency to include technology, because it can contain learning styles and improve students' perceptions of the content being presented. Using multimedia as animation can be effective for gaining attention in presenting information in the classroom and can make language teaching enjoyable for both teachers and students.

\section{Review of the Literature}

\subsection{Cognitive Theory of Multimedia and Dual-coding Theory}

Mayer (2001, pp. 4-5) suggested that learners are able to create a deeper understanding of words when they establish connections between words and pictures than from words or pictures alone. It can be assumed that using multimedia in EFL classes can make communication and learning more effective. The case of multimedia learning is based on the idea that instructional messages should be designed in light of how the human mind works with the two formats or the two information processing systems; verbal and visual (Al-Seghayer, 2001; Groot, 2000; Hulstijn, 2000; Lauferand Hill, 2000; Lyman-Hager \& Davis, 1996; Lyman-Hager,Davis, Burnett, \& Chennault, 1993).

The Cognitive Theory of Multimedia was formulated by Mayer (2001) that focused on human cognition rather than technology capacity and features. Mayer (2001) explained that the relation between Cognitive Theory and the design of multimedia instruction is an example of a dual connection between cognition and instruction: "When the relation between cognition and instruction is a two-way street, psychologists and educators communicate in ways that are mutually beneficial to both psychological theory and educational practice" (Mayer, 2001, p. 4). Multimedia learning requires that learners to engage in substantial cognitive processing during learning which takes place in the verbal and visual presentation (Mayer \& Moreno, 2003). Mayer and his colleagues suggested that certain combinations of multimedia optimize learning in terms of 
retention and transfer. Mayer (2003) explains how Cognitive Theory contributes to educational domain and presents three theory-based assumptions about how people learn from words and pictures, including, 1. Dual Channel Assumption 2. Limited Capacity Assumption; and 3. Active Processing Assumption.

The cognitive theory of multimedia relates to Paivio's dual coding theory derived from cognitive revolution of the 1960s and 1970s. It is the study of internal mental processes as a replacement for behavioristic ideas focusing on external stimulate responses (Paivio, 1990). Dual Coding Theory assumes that mental representations arise from perceptions in our sensory modalities. These modality representations can be verbal or nonverbal, including images that we have seen, heard, felt, tasted or smelled (Paivio \& Sadoski, 2001). Clark and Paivio (2005) showed that concreteness, imagery, and verbal associative processes play essential roles in several educational domains: the representation and comprehension of knowledge, learning and memory of school presentations in the visual a trial, effective instruction, individual differences, achievement motivation, test anxiety, and the learning skills. A number of studies have been conducted on the dual coding theory, for example, Holcomb and Kounios (1994) explained that Dual Coding Theory (DCT) argues that processing advantages for concrete over abstract (verbal) stimuli result from the operation of two systems (imagine and verbal) for concrete stimuli, rather than just the abstract one. These verbal and imagine systems have been linked with the left and right hemispheres of the brain.

Zavala (1999) used a dual coding approach to study reading in a high school population. The subjects were 129 EFL learners; they were given either a text-only or a text-plus-illustration condition. Learners then answered a comprehension questionnaire. Zavala concluded that the results supported dual coding because the learners who read the story with pictures outperformed those who did not. The study showed that the text with picture condition offers higher results when compared with text only. Zavala's results are congruent with Joseph and Nassar's (1995) study which examined the possibility of using dual coding theory. Joseph and Nassar examined the suitability of dual coding theory as an explanation for the results of a large number of studies using multimedia. It assumes that dual coding theory may be a reasonable explanation for many of these studies. Learners seem to learn better when related information is presented simultaneously through verbal and pictorial media than verbal or pictorial media alone. The current research is similar with Zavala (1999) and Joseph and Nassar (1995) in using multimedia and the combination of pictures with texts.

\subsection{Using multimedia in teaching English in EFL classes for Young Learners}

Multimedia plays a fundamental role in teaching English. Lin \& Chen (2007), and Siddiqi (2007) argued that multimedia is beneficial for FL learners. It is widely accepted among educationalists that multimedia instructional settings and animated models influence the way that students learn (Mayer, 2001). In multimedia instructional settings, materials are displayed in a verbal (such as on-screen text or narration) module with a pictorial form. Computer animation and cartoons can act as potential tools for creating multimedia instructional settings. Teachers can use computer animation and cartoons to present learning materials visually as they want and can control every aspect of them.

According to Mayer's Cognitive Theory (2001), the computer is a system for giving information to learners. Adding pictures, such as animation, should expand the meaning of the presented information. Thus, young learners who favor visual presentations would benefit from this process. However, multimedia presentation would not be of importance in delivering information for learners who prefer verbal present of learning materials like vocabulary. Passerini and Granger (1999) expressed that no extra learning effects are attributable to the use of animation, but did admit that animation contributes to gathering attention. But, pictures can convey a wide range of information because the human processing system is a sophisticated information processor, (Solomon, 1989). David and Dan (2002) asserted that an effective animation syllabus should be interdisciplinary and stimulate interaction and collaboration in the classroom.

\subsection{Studies Related to the Use of Multimedia and Animation in TEFL}


The impact of using multimedia in English classes on students' language achievement and goal orientation

Multimedia teaching is a new way to solve problems when it comes to young students. It contains the young learners' different needs as it uses more than one sense and attracts students' attention. Khiyabani (2014) conducted a study on the impact of multimedia on vocabulary in high schools in Iran. He investigated the effect of using multimedia on teaching vocabulary in grade two. The study attempted at identifying the significant difference in the achievement and retention of English vocabulary. Participants were 28 tenth grade students in high school in Kashmar, one of the towns of Khorasan Razavi in Iran. They were male students and all aged between 15 and 16. The findings suggested that using multimedia was more effective in acquisition and learning unknown vocabulary than traditional methods. It had a positive effect on the retention of vocabulary knowledge. Therefore, the use of multimedia provided the bridge to a deeper understanding.

Abdurrahman (2006) investigated the effect of Computer Assisted Language Learning (CALL) on elementary school students' improvement in EFL. Participants were 83 elementary school students with age of 11 to 13 years old, the academic year 2003-2004. These students were randomly chosen from Al-Tamayoz elementary school in Abu Dhabi in the UAE. Participants' material was a CD designed by an EFL teacher and a science engineer. The instrument was a pre -post achievement test. Results of this study provided evidence of the positive effect of CALL on learning English as a foreign language. Atiyyat (1995) did a study on the impact of multimedia on vocabulary. He investigated the effect of computer assisted instruction on students of tenth grade. The study attempted at identifying the significant difference in the achievement and retention of English vocabulary due to the use of CAI method. Participants were 123 tenth grade students, chosen randomly and selected from six sections at the Comprehensive Secondary School in Greater Amman. Results showed that there was a significant difference in the achievement of learning English vocabulary between the two groups in favor of the experimental group. However, there was no significant difference in the retention of English.

Mayer and Moreno (1998) also found that performance on a word-list learning task was better when learners were presented with the acoustic and visual information simultaneously. Shuell and Menter (2003) investigated the effect of multimedia on becoming more proficient writers. Participants were 86, 8th grade students in four classes from a school located in a northeast urban setting. There was a significant increase in students' scores on the organizational quality of the essays from the pretest to the posttest, especially for students who received low scores on the pre-essay. Sun and Dong (2004) also tested the effects of multimedia on supporting English vocabulary learning in a multimedia context. Sixty-seven grade1 and grade2 Chinese students (31 girls and 36 boys) were from a primary school in urban Beijing, average age was 7 years and 3 months, and having low exposure to the L2 language in their daily lives. The results indicated that learning L2 vocabulary in an animation based context without any learning support was inefficient for the young beginners. The findings also showed, learning L2 vocabulary in an animation-based context was too difficult for young beginners when no learning support was provided.

Neri (2008) studied whether a computer assisted pronunciation training program can help young learners improve word-level pronunciation in English. Participants were 11 years .Results showed that pronunciation quality of isolated words improved significantly for both groups (experimental\& control). They concluded that training with a computer-assisted pronunciation program with a simple automatic speech recognition component can lead to short-term improvements in pronunciation in contrast to those achieved by means of more traditional, teacher-led pronunciation training. Itmeizeh (2008) examined the effect of multimedia computer programs on developing English writing and reading among the Palestinian tenth graders. The subjects were 32 students, 10th grade class in a primary school for boys in Southern Directorate of Education/ Hebron. A pre- posttest was used in two groups. The experimental group was taught a multimedia program via computer. The results discovered that the experimental group performed significantly better in the posttest than in the pretest. This provided evidence for the effectiveness of using multimedia in enhancing English language learning, especially reading and writing skills.

More recently, Rostami, Akbari, and Ghanizadeh (2014) probed the impact of technology-enhanced environments as manifested in Smart Schools on EFL learners' reading comprehension ability. In their study, 
Ghanizadeh, A., \& Razavi, A.

experimental group was exposed to Smart School software program, smart board, Power Point Presentation, and World Wide Web. The results demonstrated that Smart Schools Programs have a positive and significant influence on learners' reading comprehension ability as well as on the retention of reading materials.

\section{Methodology}

\subsection{Participants and setting}

Participants in this study were students in grade eight in Navid high school, the North urban setting in Mashhad, one of the cities of Khorasan Razavi in Iran. They were female students and all aged between 14 and 15.The school was chosen because it was equipped with many facilities and spacious classrooms. It was predictable that such services would facilitate the procedures for doing this experiment. Students were divided into two groups in two classes according to their averages in grade seven high schools. Both groups consisted of a total number of 58 students, 29 in Experimental group and 29 in the control group. They all had the same exposure to English through formal classes in grade seven in high school. Equally, since they came from the same country, it is rational to assume that they shared a homogeneous EFL background. Besides, they came mostly from the same neighborhood and were at the same gender and age. At the end of the experiment, a post-test was administered to both groups.

\subsection{Design}

This study used a pre-test, a treatment, a post-test, and a goal orientation questionnaire. This selected design was shown in table 1.

\section{Table 1}

Design of the Study

\section{Stage/Activity}

\section{Pre-test}

a) Checking out the student's English achievement at the beginning of the experiment in both groups.

b) Checking out the student' goal orientation at the beginning of the experiment in both groups.

\section{Treatment}

Improving English knowledge of students in the experimental group through using multimedia.

\section{Post-test}

a) Checking out student's English achievement at the end of the experiment in both groups.

b) Checking out the student' goal orientation at the end of the experiment in both groups.

\subsection{Instrumentations}

The researchers used two instruments to accomplish the aim of the study. 1) Achievement test was used in pre-test and post- test, according to functions of "Prospect 2 "(textbook of $8^{\text {th }}$ grade), 2) Achievement goal-orientation was utilized questionnaire in control and experimental group at the beginning and at end of the experiment.

Students' goal orientation was measured by the Persian version of Achievement Goal Orientation Inventory designed by Midgley et al. (1998). The inventory comprises three subscales, 6 items for each goal orientation and a total of 18 items, and it allows responses ranging from 1 (not at all true of me) to 7 (very true of me). It represents three possible goal orientations as in table 2: 
The impact of using multimedia in English classes on students' language achievement and goal orientation

Table 2

Subscales of the AGOI along with the Equivalent Descriptions

\begin{tabular}{llcc}
\hline \multicolumn{1}{c}{ Subscale } & \multicolumn{1}{c}{ Definition } & Alpha & Items \\
\hline Mastery-approach & Attaining task-based or intrapersonal competence & 85 & $1-6$ \\
Performance-approach & Attaining normative competence & 89 & $7-12$ \\
Performance-avoidance. & Avoiding normative incompetence & 74 & $13-18$ \\
\hline
\end{tabular}

The Persian version of the scale translated and validated by Rezaee and Kareshki (2012) demonstrated acceptable reliability indices $(.81, .89 .83$, respectively). The results of assenting factor analysis established the validity of the translated version $(\mathrm{GFI}=.92, \mathrm{AGFI}=.88, \mathrm{RMSEA}=.07$ ) (as cited in Zafarmand, Ghanizadeh, \& Akbari, 2014).

\subsection{Procedure}

The present study was conducted over 22 two-hour sessions between October and December 2014. Since this comparative study consisted of two distinct approaches to English learning, the textbook (prospect 2) and material used were the same for both groups except for the medium of presentation. So, two kinds of presentations were used, using multimedia presentation (experimental group) and using traditional presentation (control group).The subjects in the experimental group including 29 students were introduced to multimedia teaching program. The program was a package that exposed learners to a variety of animations, cartoons, PowerPoint programs, songs, electronic stories in the form of text, graphics, videos and sound, all of which were intended to aid in better English comprehension. The second group including 29 students was put into the control group with the same textbook except for the medium of presentation.

\subsection{Data collection}

The total participants in the present study were 58 Iranian high school students of grade eight. The independent variable used in this study consisted of two conditions: an experimental condition in which the teacher used multimedia to teach English and a control condition in which the teacher used traditional methods. Both groups had the same number of hours of instruction, which was two periods weekly, forty minutes each and lasted for three months. The participants in the experimental group and the control group had a pre-test before the treatment began. At the end of the treatment period, a post-test was administered to both groups. A goal orientation questionnaire was also used at the beginning and at the end of experiment.

\section{Result and discussion}

\subsection{Results of the pretest}

As table 3 shows, mean pre-test scores for the experimental and control groups were 108 and 106, respectively. The independent samples T-Test showed that there was no statistically significant difference between the two groups with respect to their proficiency level before the treatment at (0.05) level, which means that the two groups are equivalent before the study.(see table 4)

\section{Table 3}

Descriptive Statistics of Proficiency Levels of Control and Experimental Groups

\begin{tabular}{lccccc}
\hline & N & Minimum & Maximum & Mean & Std. Deviation \\
\hline Control & 29 & 6.00 & 15.00 & 10.8621 & 2.38633 \\
Experimental & 29 & 6.00 & 15.00 & 10.6207 & 2.75699 \\
Valid N (listwise) & 29 & & & & \\
\hline
\end{tabular}


Ghanizadeh, A., \& Razavi, A.

\section{Table 4}

Independent Samples T-Test Showing the Results of Pretest on Achievement Level

\begin{tabular}{cccccc}
\hline & $\mathrm{t}$ & $\mathrm{df}$ & Sig. (2-tailed) & $\begin{array}{c}\text { Mean } \\
\text { Difference }\end{array}$ & Std. Error Difference \\
\hline Achievement & .356 & 56 & .723 & .24138 & .67710 \\
\hline
\end{tabular}

\subsection{Results of the post-test}

To investigate the effect of multimedia on achievement ability, the multimedia elements such as, animation, cartoons and PPP presentations were utilized in the experimental group. Now, the difference between the two groups is examined in the post-test. First, the means of the both groups in the post-test were calculated. As it can be seen in Table 5, the mean of the experimental group is 16.48, and that of the control group is 14.06. To investigate whether this difference is statistically significant, an independent-samples $t$-test was run (see Table 6). As the results of independent-samples $t$-test shows, there is a statistically significant difference between experimental and control group $(t=3.22, p<.01)$. In other words, it can be said that using multimedia in teaching English is more effective than using traditional methods of teaching.

Table 5

Descriptive Statistics of Post-Test on Achievement Level

\begin{tabular}{lccccc}
\hline & N & Minimum & Maximum & Mean & Std. Deviation \\
\hline Control & 29 & 11.00 & 17.00 & 14.0690 & 1.51023 \\
Experimental & 29 & 14.00 & 20.00 & 16.4828 & 2.04626 \\
Valid N (listwise) & 29 & & & & \\
\hline
\end{tabular}

Table 6

Independent Samples T-Test Showing the Results of post-test on Achievement Level

\begin{tabular}{cccccc}
\hline & $\mathrm{t}$ & $\mathrm{df}$ & Sig. (2-tailed) & $\begin{array}{c}\text { Mean } \\
\text { Difference }\end{array}$ & Std. Error Difference \\
\hline Achievement & 5.111 & 56 & .000 & 2.41379 & .47226 \\
\hline
\end{tabular}

To see whether the implementation of multi-media instruction had any significant impact on the achievement goal-orientations (mastery, performance, and avoidance) of the students' in experimental group, the goal orientations of the two groups on post-test were compared. The results are presented in table 7. As demonstrated by the table, the mean scores of all three goals are different across control and experimental groups.

Table 8

Descriptive Statistics of Goal-Orientation in Control and Experimental Groups

\begin{tabular}{lccccc}
\hline & $\mathrm{N}$ & Minimum & Maximum & Mean & Std. Deviation \\
\hline Mastery/ Control & 29 & 15.00 & 30.00 & 21.8276 & 4.26840 \\
Performance/Control & 29 & 15.00 & 32.00 & 24.5172 & 4.41281 \\
Avoidance/Control & 29 & 19.00 & 37.00 & 26.7931 & 5.03118 \\
Mastery/Experimental & 28 & 15.00 & 37.00 & 29.7143 & 5.02481 \\
Performance/Experimental & 28 & 20.00 & 35.00 & 29.9286 & 4.29408 \\
Avoidance/ Experimental & 28 & 21.00 & 38.00 & 30.4286 & 4.16714 \\
\hline
\end{tabular}

The results of $t$-test indicated that these differences are statistically different across the three goals: mastery $(t=6.39, p<0.05)$, performance $(t=4.69, p<0.05)$, and avoidance $(t=2.96, p<0.05)$. Although, as it can be seen, 
The impact of using multimedia in English classes on students' language achievement and goal orientation multi-media instruction had the highest impact on mastery goal.

\section{Table 9}

Independent Samples T-Tests Showing the Results of post-test on Achievement goal-orientation

\begin{tabular}{lccccc}
\hline & $\mathrm{t}$ & $\mathrm{df}$ & Sig. (2-tailed) & Mean Difference & $\begin{array}{c}\text { Std. Error } \\
\text { Difference }\end{array}$ \\
\hline Mastery & 6.394 & 55 & .000 & 7.88670 & 1.23336 \\
Performance & 4.690 & 55 & .000 & 5.41133 & 1.15383 \\
Avoidance & 2.965 & 55 & .004 & 3.63547 & 1.22597 \\
\hline
\end{tabular}

\section{Discussion}

The present study investigated the impact of using multimedia in English high school classes on language achievement and goal orientation. The results demonstrated that the application of technology-based instruction resulted in language achievement. It was also revealed that this type of instruction influenced students' achievement goal-orientation, with having the highest impact on mastery goal. In other words, the application of multi-media in language classes tends to assist them in attaining task-based or intrapersonal competence. The goal orientations seem to be directly connected to differences in students' achievement. According to obtained results, the experimental group in achievement test gained higher scores than control group in post-test. It showed experimental group after treatment (using multimedia materials) enjoyed higher levels of mastery goals which was related to effective learning and achievement in English class.

As other researchers have found, mastery goals are associated with effective learning and achievement (Middleton \& Midgley, 1997; Pajares, Britner, \&Valiante, 2000) so, mastery oriented students are intrinsically motivated, and reach high levels of performance (Elliot, 2005). Schraw, Crippen, and Hartley (2006) found that students with a strong mastery/learning orientation were higher achievers in college class, and had more adaptive behaviors referring to focusing on learners' efforts to gaining knowledge, using problem-solving strategies, and possessing more meta-cognitive awareness. Overall, higher achievers in class are more inclined towards adapting mastery/learning orientation.

As the purpose of this study was to investigate the impact of using multimedia on learners' achievement and their goal orientation according to principles of CLT as the accepted method for teaching English in Iran, and due to the results of this study, the researchers concluded that using multimedia elements in English high school classes in context of Iran can lead to following issues.

1. Cultivating Students' Interest - Currently, the traditional teaching methods and environment are out of favor while multimedia technology featuring audio and visual animation effects naturally makes learners more admittance to information besides, and this in turn enhances students' interest and motivation and their involvement in learning and teaching process.

2. Promoting Students' Communication Capacity - Traditional teaching has hindered students' capacity to comprehend structure, meaning and function of the language and makes students' passive recipients of knowledge, so it is implausible to reach the goal of communication. The multimedia technology seeks integration of teaching and learning process and provides the students with better incentives and motivates their emotions. The PPT presentations activate students' thinking; the visually and vividly presentation helps them convert English communication into capacity cultivation. Class activities as group discussion and subject discussion can also present more opportunities for communication (Roberts, 2004). Consequently, multimedia technology teaching has exclusively motivated students' positive thinking and communication skills in a social, simulated practice.

3. Widening Students' Knowledge to increase Understanding of English Culture - The multimedia can 
provide students with rich information; more than textbook (prospect 2) and help them to obtain bright cultural background, rich content, and authentic materials. Acquiring information through different channels can improve the students' knowledge. This can lead to information-sharing among students and cause them actively participate in class communication.

4. Improving Teaching Effects - Multimedia teachings enhance teaching content and class efficiency and basically break the "teacher centered" teaching. Multimedia technology creates extra visual, authentic environment for English learning that leads to cooperative and communicative learning and teaching.

5. Improving Interaction between Teacher \& Student and Student with Student - It is difficult for the students to have speaking communication in large classes. Multimedia teaching focuses on the role of students and the importance of "interaction" and the exchange between teachers and students to improve students' ability to listen and speak, and to develop their communicative competence.

6. Creating a Context for Language teaching (contextualization) - As Zhang (2006) points out, through Multimedia technology we can offer students not only rich, authentic learning materials, but also attractive pictures and pleasant sounds, that can defeat the lack of authentic language environment and motivate students' interest in learning English communicatively. So, using multimedia in EFL classes is valuable in encouraging students and teachers in learning and teaching English communication.

7. Providing Flexibility to the Content of Prospect 2 - Multimedia teaching is flexible. Students may have some problems in classroom teaching. They can use the new technology to their benefit, as manipulating the network to contact teachers, obtain new materials and receive answers by email (Brown, 2001).

Taken together, the researchers of the present study qualified the obtained results by the following reasons:

$>\quad$ The researchers attracted the students' attention as young students (8th graders) by using interesting and fantastic multimedia materials as cartoons and animation because of the colure, movement and music in it, knowing this fact that they lose attention quickly and easily.

$>$ The researchers used different activities that led to a dynamic environment in the classroom. For example, they asked the students to act what they watched, to play games, pantomime guessing words, question and answer, sing the songs, do actions, clap hands, and etc.

$>$ The researchers gave students homework as several questions in the form of multimedia materials, animations, cartoons, and CDs to watch them at home with their family, in order to create a bridge between their homes and the classroom. The researchers were attentive to the individual differences between the students. So they asked students to repeat the tasks as they felt they needed so that they could master the assignments.

Based on the results of the study, the researchers put forward a number of recommendations that can have useful impact on the educational process.

$>\quad$ Curriculum designers and decision makers should equip schools with effective visual and audio aids, wall pictures of lessons, and computers to facilitate teachers' accomplishment of the new strategies in the classes.

$>\quad$ Supplement Prospect series 1 and 2 (English textbooks in Iran) with CDs of animations and cartoons to enhance teaching English functionally and communicatively.

$>$ Provide more workshops and teachers training courses (TCC) to improve teachers' ability in developing multimedia materials for teaching English. 
The impact of using multimedia in English classes on students' language achievement and goal orientation

\section{References}

Agina, M. A. (2003). The advantages and disadvantages of the animation technology in education and training. Unpublished Masteral thesis, University of Enschede, The Netherlands.

Abdurrahman, A. (2006). The effect of computer assisted language learning (CALL) on United Arab Emirates English as a foreign language (EFL) school students' achievement and attitudes. Journal of Interactive Learning Research, 6(2), 112-141.

Al-Seghayer, K. (2001). The effect of multimedia annotation modes on L2 vocabulary acquisition: A comparative study. Language Learning and Technology, 5(1), 202-232.

Atiyyat, I. (1995). The effect of computer assisted instruction upon tenth grade students' mastering of English vocabulary. Unpublished Masteral thesis. University of Jordan, Jordan.

Brown, H. D. (2001). Teaching by principle .New York: Longman.

Clark, J., \& Paivio, L. (2005). Dual coding theory and education. Educational Psychology Review, 3(3), $149-210$. http://dx.doi.org/10.1007/BF01320076

David, E., \& Dan, B. (2002). A collaborative and interdisciplinary computer animation. The MIT Press Course Leonardo, 35(1), 83-86.

Elliot, A. J. (2005). A conceptual history of the achievement goal construct. In A. J. Elliot \& C. S. Dweck (Eds.). Handbook of competence and motivation (pp. 52-72). New York, New York: The Guilford Press.

Groot, P. J. M. (2000). Computer assisted second language vocabulary acquisition. Language Learning and Technology, 4(1), 60-81.

Holcomb, P., \& Kounios, J. (1994). Concreteness effects in semantic processing: ERP evidence supporting dual-coding theory. Journal of Experimental Psychology: Learning Memory, and Cognition, 20(4), 804-823. http://dx.doi.org/10.1037/0278-7393.20.4.804

Itmeizeh, M. (2008). The effect of multimedia computer programs on developing writing and reading comprehension among the Palestinian tenth graders and their attitudes towards language. Unpublished Doctoral dissertation. Ain Shams University, Egypt.

Li, X. (2009). The advantages and disadvantages of multimedia teaching. Chinese Journal of Electric Power Technique, 4, 43-44.

Joseph, R., \& Nassar, (1995). Dual coding as a possible explanation for the effects of multimedia on learning. Georgia Institute of Technology, Georgia.

Lin, H., \& Chen, T.(2007). Reading authentic EFL text using visualization and advance organizers in a multimedia learning environment. Language Learning and Technology, 11(3), 83-106.

Mayer, R. (2001). Multimedia learning. Cambridge University Press: USA. http://dx.doi.org/10.1017/CBO9781139164603

Mayer, R., \& Moreno, R. (2003). Nine ways to reduce cognitive load in multimedia learning. Educational Psychology, 38(1), 43-52. http://dx.doi.org/10.1207/S15326985EP3801_6

Middleton, M. J., \& Midgley, C. (1997).Avoiding the demonstration of lack of ability: An underexplored aspect of goal theory. Journal of Educational Psychology, 89, 710-718. http://dx.doi.org/10.1037/0022-0663.89.4.710

Midgley, C., Kaplan, A., Middleton, M., Maehr, M. L., Urdan, T., Anderman, L. H., Anderman, E., \& Roeser, R. (1998). The development and validation of scales assessing students' achievement goal orientations. Contemporary Educational Psychology, 23(2), 113-131. http://dx.doi.org/10.1006/ceps.1998.0965

Neri, A. (2008). The effectiveness of computer-based speech corrective feedback for improving segmental quality in L2 Dutch. RECALL, 20(2), 225-243. http://dx.doi.org/10.1017/S0958344008000724

Paivio, A. (1990). Mental representation: Dual coding approach. Oxford University Press: London. http://dx.doi.org/10.1093/acprof:oso/9780195066661.001.0001

Paivio, A., \& Sadoski, M. (2001). Imagery and text: Dual coding theory of reading and writing. Lawrence Erlbaum Associates: London.

Pajares, F., Britner, S., \&Valiante, G. (2000).Relation between achievement goals and self-beliefs of middle school students in writing and science. Contemporary Educational Psychology, 25, 406-422. 
Ghanizadeh, A., \& Razavi, A.

http://dx.doi.org/10.1006/ceps.1999.1027

Passerini, K., \& Granger, M. (1999). A developmental model for distance learning using the Internet. The George Washington University: USA.

Rostami, S., Akbari, O., \& Ghanizadeh, A. (2015). The effect of smart school programs on EFL reading comprehension in an academic context. International Journal of Research Studies in Educational Technology, 4(1), 1-10. http://dx.doi.org/10.5861/ijrset.2014.936

Schraw, G., Crippen, K. J., \& Hartley, K. (2006). Promoting self-regulation in science education: Metacognition as part of a broader perspective on learning. Research in Science Education, 36, 111-139. http://dx.doi.org/10.1007/s11165-005-3917-8

Sun, Y., \& Dong, O. (2004). An experiment on supporting children's English vocabulary learning in multimedia context. Foreign Languages \& Literature, 17(2), 131-147. http://dx.doi.org/10.1080/0958822042000334217

Warschauer, M., \& Healey, D. (1998). Computers and language learning: An overview, Language Teaching, 31(1), 57-71. http://dx.doi.org/10.1017/S0261444800012970

Zavala, F. (1999). Reading an illustrated and non-illustrated story: dual coding in the foreign language classroom. Unpublished masteral thesis, Illinois State University.

Zhang, B. (2008). Presentation modes and vocabulary learning and retention effects. Retrieved from http://bibliotecavirtualut.suagm.edu/Glossa2/Journal/Presentation_Modes_and_Vocabulary_Learning

Zafarmand, A., Ghanizadeh, A., \& Akbari, O. (2014). a structural equation modeling of EFL learners' goal orientation, metacognitive awareness, and self-efficacy. Advances in Language and Literary Studies, $5(6), 112-124$. 